\title{
Diversity of partial RNA-dependent RNA polymerase gene sequences of Soybean blotchy mosaic virus isolates from different host-, geographical- and temporal origins \\ Elrea Strydom ${ }^{\mathrm{a}, \mathrm{b}}$
}

${ }^{a}$ Department of Microbiology and Plant Pathology, University of Pretoria, Pretoria, 0002, South Africa; ${ }^{b}$ Forestry and Agricultural Biotechnology Institute, University of Pretoria, Pretoria, 0002, South Africa.

elrea.appelgryn@fabi.up.ac.za

\section{Gerhard Pietersen $^{a, b, c}$}

${ }^{\mathrm{C}}$ Genetics Department, University of Stellenbosch, Stellenbosch, 7600, South Africa; ${ }^{a}$ Department of Microbiology and Plant Pathology, University of Pretoria, Pretoria, 0002, South Africa; ${ }^{b}$ Forestry and Agricultural Biotechnology Institute, University of Pretoria, Pretoria, 0002, South Africa.

Corresponding author at: Genetics Department, University of Stellenbosch, Stellenbosch, 7600, South Africa.

gerhard.pietersen@up.ac.za

$+(27) 124203265$

\section{Abstract}

Infection of soybean by the plant cytorhabdovirus Soybean blotchy mosaic virus results in significant yield losses in the temperate, lower-lying soybean production regions of South Africa. A 277 bp portion of the RNA-dependent RNA polymerase gene of 66 Soybean blotchy mosaic virus isolates from different hosts, geographical locations in South Africa, and time of collection spanning 16 years were amplified by RT-PCR and sequenced to investigate the genetic diversity of isolates. Phylogenetic reconstruction revealed three main lineages, designated Groups A, B and C, with isolates grouping primarily according to geographic origin. Pairwise nucleotide identities ranged between $85.7 \%$ and $100 \%$ among all isolates, with isolates in Group A exhibiting the highest degree of sequence identity, and isolates of Groups A and B being more closely related to each other than to those in Group C. This is the first study investigating the genetic diversity of SbBMV.

Keywords: Soybean blotchy mosaic virus; RNA-dependent RNA polymerase gene, maximumlikelihood analysis; pairwise nucleotide similarity 
Soybean blotchy mosaic virus (SbBMV) is provisionally classified as a member of the genus Cytorhabdovirus within the family Rhabdoviridae based on viral shape, size, distribution of viral particles in plant cells and limited sequence information [1]. Members of the Rhabdoviridae have single-stranded or bipartite RNA genomes of negative polarity between $12 \mathrm{~kb}$ and $14.5 \mathrm{~kb}$ in size [2-4]. Rhabdovirus genomes encode six structural proteins, the nucleoprotein $(\mathrm{N})$, phosphoprotein $(P)$, matrix protein $(M)$, glycoprotein $(G)$ and RNA-dependent RNA polymerase (L). Eighteen genera are recognized within the family Rhabdoviridae, of which four, Nucleorhabdovirus, Cytorhabdovirus, Dichorhavirus and Varicosavirus infect plants [4]. The plant cyto- and nucleorhabdoviruses also encode one to four accessory proteins hypothesized to be involved in movement from cell to cell and other unknown functions.

Infection of soybean by SbBMV is characterized by blotchy mosaic symptoms on leaves early in the soybean production season, with symptom severity and incidence declining with time. The disease has only been detected in the lower lying soybean production areas of South Africa such as Limpopo, Mpumalanga, North West and KwaZulu-Natal $[5,6]$. The virus has been shown to be mechanically transmissible to soybean and Nicotiana benthamiana, and the leafhopper Peragallia carboverdensis (Cicadellidae, Agalliinae) was identified as an insect vector of SbBMV [1], but the whole genome sequence of SbBMV still needs to be determined.

Despite the economic importance of diseases caused by plant rhabdoviruses, they remain relatively poorly studied when compared to their animal-infecting counterparts. The amount of sequence information (both partial gene sequences and whole genome sequences) generated for plant rhabdoviruses has increased in the last few years, but studies on the evolutionary relationships and variability of plant rhabdoviruses still largely rely on portions of a gene sequence or full gene sequences of a few gene regions [7-10]. The RNA-dependent RNA polymerase protein has conserved RNA-binding and polymerase domains, which are valuable for phylogenetic analysis, and consequently these are often used to infer evolutionary relationships and assess genetic diversity in plant rhabdoviruses [7, 8, 11-13].

The phylogenetic relationships and genetic diversity of SbBMV isolates have not been evaluated, and have important implications for viral diagnostics and the effective detection of all variants in a population, as well as understanding processes such as evolution and interactions between viruses and their hosts and vectors [14]. In this paper, partial sequences of the L gene of SbBMV isolates were generated by RT-PCR and Sanger sequencing and analyzed to assess the genetic diversity of SbBMV isolates from different plant and insect hosts, geographical 
origins in South Africa and three general collection periods spanning 16 years. Maximumlikelihood phylogenetic reconstruction was used to infer phylogenetic relationships between isolates, and $p$-distances were calculated to assess genetic variability.

Isolates originating from plant hosts were obtained either as dried leaf material from the Virus, Antiserum and Seroreagent (PVAS) collection at the Agricultural Research Council-Plant Protection Research Institute (ARC-PPRI), in Pretoria, South Africa, or fresh leaf material displaying the typical blotchy mosaic symptoms associated with SbBMV. Samples were collected in the Brits (North West), Thabazimbi (Limpopo), Pretoria (Gauteng), Loskop Irrigation Scheme (Mpumalanga), Schoemanskloof (Mpumalanga), Dundee (KwaZulu-Natal) and Lusikisiki (Eastern Cape) areas of South Africa. Isolates obtained from asymptomatic alternative hosts of SbBMV, Gymnosporia buxifolia, and Lamium amplexicaule were also included. Each plant was assigned a unique accession number and fresh plant material samples were stored at $4^{\circ} \mathrm{C}$ prior to homogenization with liquid nitrogen. Plant total RNA was extracted using $1.8 \mathrm{ml}$ of CTAB buffer per sample according to the method described by White and co-workers [15] modified by the omission of spermidine in the CTAB buffer, and centrifugation for $15 \mathrm{~min}$. Individuals of $P$. caboverdensis were collected from soybean cultivar trials in Brits, North West in which high incidences of the disease was observed, and preserved in $100 \%$ ethanol until processed. RNA was extracted from individuals of $P$. caboverdensis using the method described by Mallory and co-workers [16] prior to RT-PCR and sequencing.

Partial $L$ gene sequences of 66 isolates (Table 1) were determined. The Soyblotch $F\left(5^{\prime}\right.$ CTTTGCCCAACTGGACTCCC 3') and Soyblotch R (5' TCCAAACAGTCTTCCCAGGC 3') primer pair were designed to amplify a 354 bp portion of $522 \mathrm{nt}$ of the SbBMV $L$ gene which is available in the National Centre for Biotechnology Information (NCBI) database (EU877231) [1, 17]. RT-PCR using the Soyblotch primer pair was performed as previously described [17]. Samples were submitted for Sanger sequencing using an ABI 3500xL automated sequencer at the University of Pretoria, South Africa, and sequences subjected to a Basic Local Alignment Search Tool (BLASTn) search in the NCBI database in order to confirm the identity of isolates as SbBMV. Forward and reverse raw sequence reads were assembled using BioEdit software [18], and consensus sequences were manually curated and aligned online using Mafft [19] with default parameters. Alignments were trimmed from both the $5^{\prime}$ and $3^{\prime}$ ends in BioEdit to minimise the influence of gaps present in alignments. Phylogenetic trees were constructed using the maximum-likelihood method based on the Tamura-Nei model [22] in MEGA software version 6 [20] with 1000 replicates of bootstrap analysis, and Northern cereal mosaic virus 
Table I. Host, geographical origin, year of collection and accession information of SbBMV isolates used in this study.

\begin{tabular}{|c|c|c|c|c|c|}
\hline Isolate & $\begin{array}{l}\text { Genbank Accession } \\
\text { number }\end{array}$ & Host & Origin & Year & Group \\
\hline $91 / 0084$ & MF964900 & Glycine max & Loskop Irrigation Scheme, Mpumalanga, South Africa & 1991 & A \\
\hline $91 / 0085$ & MF964901 & Glycine max & Loskop Irrigation Scheme, Mpumalanga, South Africa & 1991 & A \\
\hline $91 / 0088$ & MF964902 & Glycine max & Loskop Irrigation Scheme, Mpumalanga, South Africa & 1991 & A \\
\hline $91 / 0090$ & MF964903 & Glycine max & Loskop Irrigation Scheme, Mpumalanga, South Africa & 1991 & A \\
\hline $91 / 0091$ & MF964871 & Glycine max & Loskop Irrigation Scheme, Mpumalanga, South Africa & 1991 & A \\
\hline $91 / 0095$ & MF964872 & Glycine max & Loskop Irrigation Scheme, Mpumalanga, South Africa & 1991 & A \\
\hline $92 / 0010$ & MF964904 & Glycine max & Dundee, KwaZulu-Natal & 1992 & A \\
\hline $92 / 0026$ & MF964905 & Glycine max & Loskop Irrigation Scheme, Mpumalanga, South Africa & 1992 & A \\
\hline $92 / 0033$ & MF964908 & Glycine max & Loskop Irrigation Scheme, Mpumalanga, South Africa & 1992 & A \\
\hline $92 / 0034$ & MF964906 & Glycine max & Loskop Irrigation Scheme, Mpumalanga, South Africa & 1992 & $\mathrm{C}$ \\
\hline $92 / 0404$ & MF964909 & Glycine max & Thabazimbi, Limpopo, South Africa & 1992 & $\mathrm{C}$ \\
\hline $94 / 0398$ & MF964873 & Glycine max & Brits, North West, South Africa & 1994 & A \\
\hline $94 / 2068$ & MF964912 & Glycine max & Loskop Irrigation Scheme, Mpumalanga, South Africa & 1994 & A \\
\hline $94 / 2074$ & MF964911 & Glycine max & Loskop Irrigation Scheme, Mpumalanga, South Africa & 1994 & A \\
\hline $94 / 2089$ & MF964870 & Glycine max & Loskop Irrigation Scheme, Mpumalanga, South Africa & 1994 & A \\
\hline $95 / 0011$ & MF964913 & Glycine max & Loskop Irrigation Scheme, Mpumalanga, South Africa & 1995 & A \\
\hline $95 / 0013$ & MF964914 & Glycine max & Loskop Irrigation Scheme, Mpumalanga, South Africa & 1995 & A \\
\hline $95 / 0015$ & MF964916 & Glycine max & Loskop Irrigation Scheme, Mpumalanga, South Africa & 1995 & $\mathrm{~B}$ \\
\hline $95 / 0017$ & MF964917 & Glycine max & Loskop Irrigation Scheme, Mpumalanga, South Africa & 1995 & A \\
\hline $95 / 0038$ & MF964918 & Glycine max & Thabazimbi, Limpopo, South Africa & 1995 & $\mathrm{C}$ \\
\hline $95 / 0073$ & MF964919 & Glycine max & Pretoria, Gauteng, South Africa & 1995 & $\mathrm{C}$ \\
\hline $03 / 4013$ & MF964910 & Glycine max & Lusikisiki, Eastern Cape, South Africa & 2003 & $\mathrm{~B}$ \\
\hline $03 / 4025$ & MF964896 & Glycine max & Lusikisiki, Eastern Cape, South Africa & 2003 & $\mathrm{~B}$ \\
\hline $03 / 4029$ & MF964897 & Glycine max & Lusikisiki, Eastern Cape, South Africa & 2003 & $\mathrm{~B}$ \\
\hline $03 / 4030$ & MF964898 & Glycine max & Lusikisiki, Eastern Cape, South Africa & 2003 & $\mathrm{~B}$ \\
\hline $03 / 4033$ & MF964899 & Glycine max & Lusikisiki, Eastern Cape, South Africa & 2003 & $\mathrm{~B}$ \\
\hline $14 / 3001$ & MF964874 & Glycine max & Brits, North West, South Africa & 2014 & $\mathrm{C}$ \\
\hline $14 / 3002$ & MF964875 & Glycine max & Brits, North West, South Africa & 2014 & $\mathrm{C}$ \\
\hline $14 / 3005$ & MF964876 & Glycine max & Brits, North West, South Africa & 2014 & $\mathrm{C}$ \\
\hline $15 / 3002$ & MF964877 & Glycine max & Brits, North West, South Africa & 2015 & $\mathrm{C}$ \\
\hline $15 / 3006$ & MF964878 & Glycine max & Brits, North West, South Africa & 2015 & $\mathrm{C}$ \\
\hline $15 / 3011$ & MF964879 & Glycine max & Brits, North West, South Africa & 2015 & $\mathrm{C}$ \\
\hline $15 / 3067$ & MF964880 & Glycine max & Loskop Irrigation Scheme, Mpumalanga, South Africa & 2015 & $\mathrm{~B}$ \\
\hline $15 / 3069$ & MF964881 & Glycine max & Loskop Irrigation Scheme, Mpumalanga, South Africa & 2015 & $\mathrm{C}$ \\
\hline $15 / 3086$ & MF964882 & Glycine max & Loskop Irrigation Scheme, Mpumalanga, South Africa & 2015 & A \\
\hline $15 / 3146$ & MF964886 & Glycine max & Schoemanskloof, Mpumalanga, South Africa & 2015 & $\mathrm{~B}$ \\
\hline $15 / 3147$ & MF964887 & Glycine max & Schoemanskloof, Mpumalanga, South Africa & 2015 & $\mathrm{~B}$ \\
\hline $15 / 3155$ & MF964888 & Glycine max & Schoemanskloof, Mpumalanga, South Africa & 2015 & $\mathrm{~B}$ \\
\hline $15 / 3156$ & MF964889 & Glycine max & Schoemanskloof, Mpumalanga, South Africa & 2015 & $\mathrm{~B}$ \\
\hline $15 / 3250$ & MF964890 & Glycine max & Brits, North West, South Africa & 2015 & $\mathrm{C}$ \\
\hline $16 / 4129$ & MF964893 & Glycine max & Brits, North West, South Africa & 2016 & $\mathrm{C}$ \\
\hline $16 / 4131$ & MF964894 & Glycine max & Brits, North West, South Africa & 2016 & $A$ \\
\hline $16 / 4132$ & MF964920 & Glycine max & Brits, North West, South Africa & 2016 & $\mathrm{C}$ \\
\hline $16 / 4134$ & MF964921 & Glycine max & Brits, North West, South Africa & 2016 & $\mathrm{C}$ \\
\hline $16 / 4427$ & MF964892 & Gymnosporia buxifolia & Brits, North West, South Africa & 2016 & $\mathrm{C}$ \\
\hline $16 / 4712$ & MF964891 & Lamium amplexicaule & Brits, North West, South Africa & 2016 & $\mathrm{C}$ \\
\hline $17 / 5000$ & MF964922 & Glycine max & Brits, North West, South Africa & 2017 & $A$ \\
\hline $17 / 5002$ & MF964923 & Glycine max & Brits, North West, South Africa & 2017 & C \\
\hline $17 / 5003$ & MF964924 & Glycine max & Brits, North West, South Africa & 2017 & $\mathrm{C}$ \\
\hline $17 / 5004$ & MF964925 & Glycine max & Brits, North West, South Africa & 2017 & $\mathrm{C}$ \\
\hline $17 / 5005$ & MF964926 & Glycine max & Brits, North West, South Africa & 2017 & $\mathrm{C}$ \\
\hline $17 / 5006$ & MF964927 & Glycine max & Brits, North West, South Africa & 2017 & $\mathrm{C}$ \\
\hline $17 / 5008$ & MF964928 & Glycine max & Brits, North West, South Africa & 2017 & $\mathrm{C}$ \\
\hline $17 / 5501$ & MF964929 & $\begin{array}{l}\text { Peragallia } \\
\text { caboverdensis }\end{array}$ & Brits, North West, South Africa & 2017 & $\mathrm{C}$ \\
\hline $17 / 5503$ & MF964930 & $\begin{array}{l}\text { Peragallia } \\
\text { caboverdensis }\end{array}$ & Brits, North West, South Africa & 2017 & C \\
\hline $17 / 5505$ & MF964931 & $\begin{array}{l}\text { Peragallia } \\
\text { caboverdensis }\end{array}$ & Brits, North West, South Africa & 2017 & $\mathrm{C}$ \\
\hline $17 / 5506$ & MF964932 & $\begin{array}{l}\text { Peragallia } \\
\text { caboverdensis }\end{array}$ & Brits, North West, South Africa & 2017 & $\mathrm{C}$ \\
\hline $17 / 5507$ & MF964933 & $\begin{array}{l}\text { Peragallia } \\
\text { caboverdensis }\end{array}$ & Brits, North West, South Africa & 2017 & C \\
\hline $17 / 5508$ & MF964934 & $\begin{array}{l}\text { Peragallia } \\
\text { caboverdensis }\end{array}$ & Brits, North West, South Africa & 2017 & $\mathrm{C}$ \\
\hline $17 / 5539$ & MF964935 & $\begin{array}{l}\text { Peragallia } \\
\text { caboverdensis }\end{array}$ & Brits, North West, South Africa & 2017 & $\mathrm{C}$ \\
\hline $17 / 5633$ & MF964895 & $\begin{array}{l}\text { Peragallia } \\
\text { caboverdensis }\end{array}$ & Brits, North West, South Africa & 2017 & C \\
\hline
\end{tabular}


(NCMV) (NC_002251.1) as outgroup. Pairwise nucleotide distances ( $p$-distance) for the same dataset was determined using SDT v.1.2 software [21], and is presented as colour-coded blocks.

Analysis of $277 \mathrm{bp}$ of the $\mathrm{L}$ gene of $66 \mathrm{SbBMV}$ isolates using the maximum-likelihood method is presented in Fig 1. Phylogenetic analysis showed segregation of isolates into three main lineages, referred to here as groups A, B and C. Group A was dominated by isolates collected in the 1990s from the Loskop Irrigation Scheme, but also contains isolates from two other geographical locations (Schoemanskloof and Dundee) and the more recently isolated accessions 15/3086 (Loskop Irrigation Scheme), 15/3137 (Schoemanskloof), 16/4131 (Brits) and $17 / 5000$ (Brits). Clade B consists of two sub-clades mostly of isolates collected from Lusikisiki in 2003 and Schoemanskloof during 2015, with the exception of isolates 15/3067 and 95/0015, which were collected in the Loskop Irrigation Scheme. Group C is mostly composed of isolates collected from soybean in Brits, but isolates from Thabazimbi (2), Pretoria (1) and Loskop Irrigation Scheme (3), the leafhopper vector $P$. caboverdensis and the alternative plant hosts $G$. buxifolia and $L$. amplexicaule represented the rest of the clade.

A clear correlation by grouping of isolates and geographic origin was observed. Group A, the two sub-clades within Group B and Group C were each dominated by isolates from a single geographic location, which were the Loskop Irrigation Scheme, KwaZulu-Natal and Schoemanskloof, and Brits respectively. The presence of isolates from other locations within each of these clades indicated that these isolates were not geographically isolated with respect to gene flow, but rather that each region might select for specific strains or genotypes based on specific selection pressures present. As an example, the high variability and absence of isolates from Lusikisiki in Groups $A$ and $C$ and the limited presence of isolates from Schoemanskloof in the other groups might be the result of competitive exclusion. Enhanced interactions of isolates in Groups $A$ and $C$ with plant or insect hosts may lead to their apparent dominance, as also described in Lettuce necrotic yellows virus (LNYV) [23]. Soybean cultivar selection varies greatly in different regions, as does the natural vegetation, which may serve as alternative hosts, and these may act in strain selection, furthermore insect vectors often select for specific genotypes adapted to plant-vector systems [24]. Multiple genetically distinct strains of SbBMV thus exist in each location, in which one genotype is favoured, increasing their prevalence. 

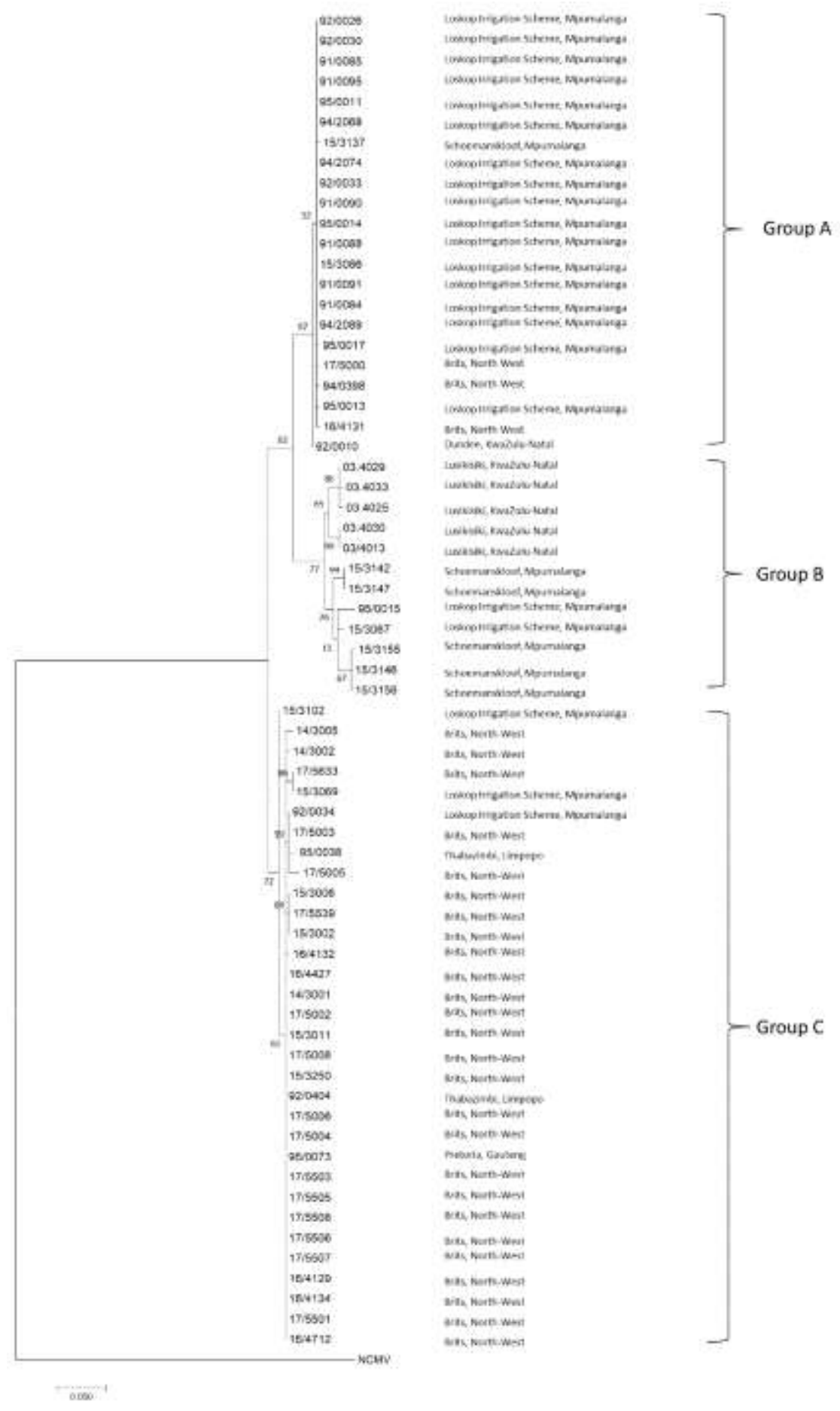

Fig 1. Maximum-likelihood phylogenetic analysis of partial $L$ genes of 66 Soybean blotchy mosaic virus isolates from different geographical origins and hosts. Phylogenetic tree is mid-point rooted, and bootstrap percentages (1000 replicates) are indicated at nodes of each clade. Northern cereal mosaic virus (NC_002251.1) was used as outgroup. Evolutionary analysis was conducted in MEGA 6. 
Little is known of the epidemiology and variation of $P$. caboverdensis. Accession 15/3102 appears to be the founder sequence of Group C, and its association with mainly accessions from Brits suggests an introduction of SbBMV from the Loskop Irrigation Scheme into Brits in the early 1990s. The manner in which this may have occurred is unclear. Irrigation schemes are used at both Loskop and Brits, and similar crops are grown in both areas. Movement of plant material between these regions and/or enhanced vector breeding associated with high rainfall (irrigation) might have facilitated the introduction of $P$. caboverdensis into Brits. Lastly, rising temperatures can also increase the range, densities and migration potential of host plants and insect vectors [25]. Lengthened breeding seasons for $P$. caboverdensis or expansion of the geographic ranges of alternative hosts, acting as a corridor for the spread of the vector, could also be plausible.

Clustering of isolates according to geographic origin has also been reported in other plant rhabdoviruses. Investigation of more than $1 \mathrm{kB}$ of sequence data for each of $14 \mathrm{~N}$ and $19 \mathrm{~L}$ genes of Taro vein chlorosis virus isolates showed distinctive relationships between viral subgroups and geographical origin in the Pacific Islands [8]. This was also observed in a study which focussed on conserved regions of the $L$ gene of 20 Eggplant mottled dwarf virus (EMDV) isolates, where phylogenetic analysis indicated two distinct genetic groups based on geographical origin [12]. Furthermore, analysis of sequences corresponding to the $N, X, P, Y, G$ and $L$ genes, as well as the untranslated regions of EMDV from different alternative hosts generally clustered isolates into three subgroups based on geographical origin, and not host [14].

The lack of a correlation between the clustering of isolates and host in EMDV isolates [14] was also observed in this study. Accessions isolated from different hosts such as soybean, other alternative plant hosts and the insect vector $P$. caboverdensis all grouped together in clade $C$, illustrating an observed absence of divergence of SbBMV in different host backgrounds. A correlation by grouping of isolates and date of collection was also absent. Although the majority of isolates originating from the early 1990's clustered together in Group A, older collection accessions were also present in Groups B and C, and similarly, isolates collected more recently present in clade $A$. The isolates in the two sub-clades which represent Group B were also collected more than 10 years apart. Similarly, sequencing and phylogenetic analysis of the complete $\mathrm{N}$ gene of eight LNYV isolates from Australia also showed no temporal separation in subgroups [10]. However, this is in contrast to later studies of LNYV which reported the 
clustering of more recently collected isolates in a subgroup, with older isolates forming a distinct clade [23].

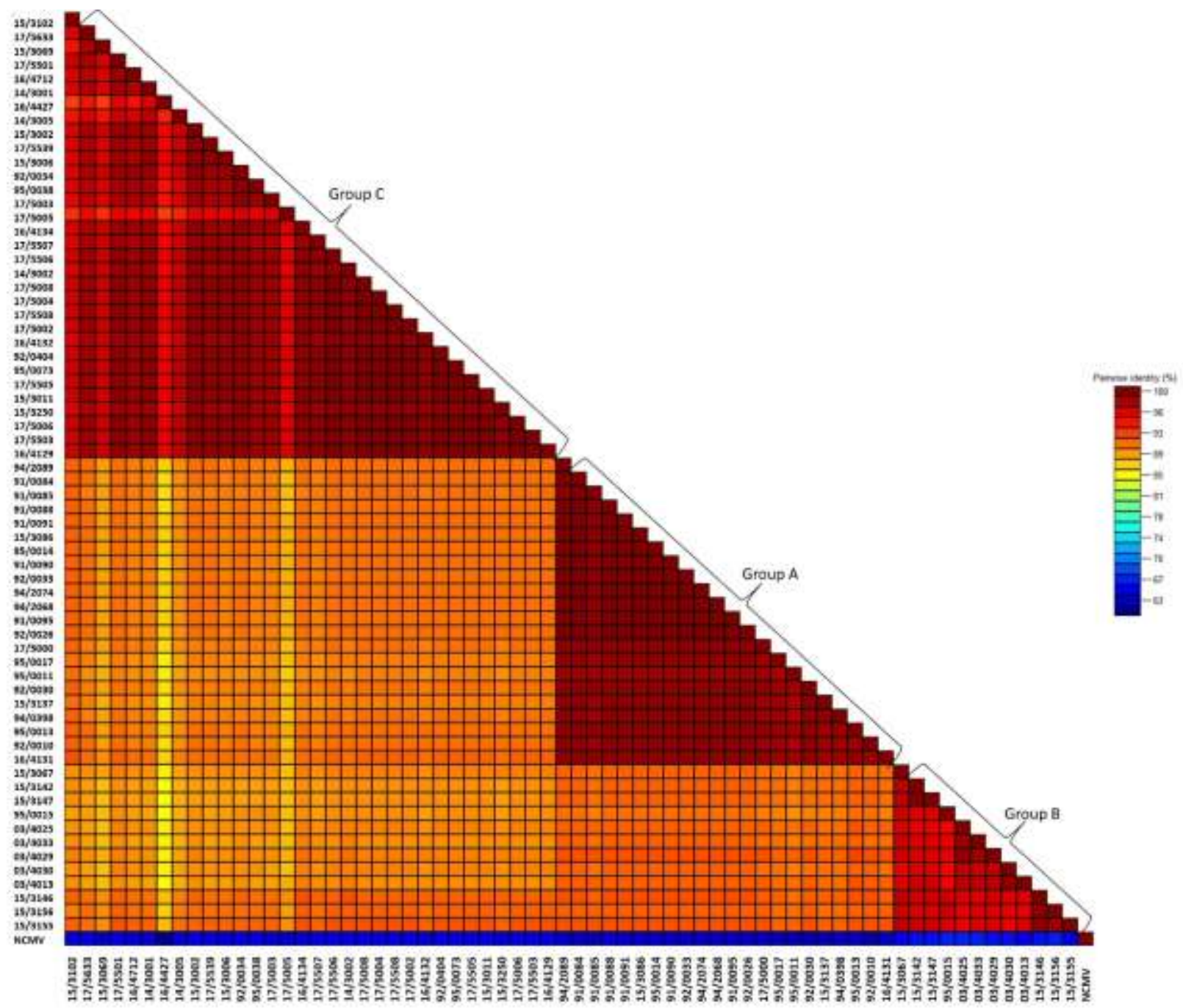

Fig 2. Graphical representation of pairwise nucleotide identities of 66 Soybean blotchy mosaic virus isolates used in this study with percentage identity scale. Pairwise nucleotide identities were obtained with SDT v1.2 software. Northern cereal mosaic virus (NC_002251.1) was used as outgroup in phylogenetic analysis, and is included here. Origin and hosts of isolates are listed in Table 1.

Pairwise nucleotide identities ranged between 98.5\%-100\%, 95.1\%-100\% and 92.7\%-100\% between SbBMV isolates in Groups A, B and C respectively (Fig 2). Between isolates of Groups $A$ and $B$, the highest nucleotide similarity was $92.7 \%$, and the lowest $90 \%$. The minimum nucleotide identity between clade $A$ and clade $C$ was 86.3 , and the maximum 92.1. The 
minimum sequence identity between clades $B$ and $C$ was $85.7 \%$, and the maximum $92.4 \%$. Isolates within Group A showed the least amount of genetic diversity, while those in Group C showed the highest amount of sequence diversity. Clades A and B appear to more closely related to each other than to Group $C$, as indicated by the larger minimum and maximum nucleotide identities. It will be important to determine the whole genome of representative samples from each clade.

A previous study reported that NCMV had the highest nucleotide similarity to SbBMV (60.7\%) among the cytorhabdoviruses [1], and in this study, nucleotide similarities between SbBMV isolates and NCMV varied between $57.8 \%$ and $62.8 \%$. Despite the use of the closest member in the genus Cytorhabdovirus as outgroup, a long root was still obtained, which is attributed to the diversity present in different species of the cyto- and nucleorhabdoviruses. Cyto- and nucleorhabdoviruses show higher levels of genetic diversity than other genera in the Rhabdoviridae such as the lyssaviruses [11], which could be the result of purifying selection in the lyssaviruses or a more recent evolution.

In this study, we report an increase in the known distribution of SbBMV, now confirmed to also be present in the Eastern Cape, furthermore we demonstrate the presence of diverse populations of SbBMV isolates for the first time. In future, additional, longer gene regions or whole genome sequences should be used to confirm evolutionary relationships inferred here, and can be used to determine whether the genetic variation observed in a portion of the $L$ gene also translates to the full genome sequence.

\section{Acknowledgements}

Funding was provided by the Association of African Universities (AAU), the Genomics Research Institute (GRI) at the University of Pretoria, South Africa and through the National Research Foundation Incentive Grant for Rated Scientists. 


\section{References}

1. Lamprecht, R.L., et al., Soybean blotchy mosaic virus, a new cytorhabdovirus found in South Africa. Plant Dis, 2010. 94(11): p. 1348-1354.

2. Jackson, A.O., et al., Biology of plant rhabdoviruses. Annu Rev Phytopathol, 2005. 43: p. 623-660.

3. Dietzgen, R.G., et al., The family Rhabdoviridae: mono- and bipartite negative-sense RNA viruses with diverse genome organization and common evolutionary origins. Virus Res, 2017. 227: p. 158-170.

4. Amarasinghe, G.K., et al., Taxonomy of the order Mononegavirales: update 2017. Arch Virol, 2017. 162(8): p. 2493-2504.

5. Pietersen, G. and H.M. Garnett, A survey for the viruses of soybeans (Glycine max) in the Transvaal, South Africa. Phytophylactica, 1990. 22(1): p. 35-40.

6. Pietersen, G., et al., Relative abundance of soybean viruses in South Africa. Afr Plant Prot, 1998. 4(2): p. 65-70.

7. Klerks, M.M.J., et al., Detection and tentative grouping of Strawberry crinkle virus isolates. Eur J Plant Pathol 2004. 110: p. 45-52.

8. Revill, P., et al., Taro vein chlorosis virus: characterization and variability of a new nucleorhabdovirus. J Gen Virol, 2005. 86(2): p. 491-499.

9. Talbi, C., et al., Genetic diversity of perch rhabdovirus isolates based on the nucleoprotein and glycoprotein genes. Arch Virol, 2011. 156: p. 2133-2144.

10. Callaghan, B. and R.G. Dietzgen, Nucleocapsid gene variability reveals two subgroups of Lettuce necrotic yellows virus. Arch Virol 2005. 150: p. 1661-1667.

11. Bourhy, $H_{\text {. }}$, et al., Phylogenetic relationships among rhabdoviruses inferred using the $L$ polymerase gene. J Gen Virol, 2005. 86(10): p. 2849-2858.

12. Parrella, G. and B. Greco, Sequence variation of block III segment identifies three distinct lineages within Eggplant mottled dwarf virus isolates from Italy, Spain and Greece. Acta Virol, 2016. 60: p. 100-105.

13. Petrzik, K., Bioinformatic analysis of the $L$ polymerase gene leads to discrimination of new rhabdoviruses. J Phytopathology, 2012. 160(7-8): p. 377-381.

14. Pappi, P.G., et al., Genetic variation of Eggplant mottled dwarf virus from annual and perennial plant hosts. Arch Virol, 2016. 161(3): p. 631-639. 
15. White, E.J., et al., Modified cetyltrimethylammonium bromide method improves robustness and versatility: The benchmark for plant RNA extraction. Biotechnol J, 2008. 3: p. 1424-1428.

16. Mallory, A., et al., HC-Pro suppression of transgene silencing eliminates the small RNAs but not transgene methylation or the mobile signal. Plant Cell, 2001. 13(3): p. 571-583.

17. Strydom, E. and G. Pietersen, Alternative hosts and seed transmissibility of Soybean blotchy mosaic virus. Eur J Plant Pathol, 2017 doi:10.1007/s10658-017-1361-z.

18. Hall, T.A., BioEdit: a user-friendly biological sequence allignment editor and analysis program for Windows 95/98NT. Nucleic Acids Symp Ser, 1999. 41: p. 95-98.

19. Katoh, K., et al., A novel method for rapid multiple sequence alignment based on fast fourier transform. Nucleic Acids Res, 2002. 30(14): p. 3059-3066.

20. Tamura, K., et al., MEGA5: Molecular evolutionary genetics analysis using maximum likelihood, evolutionary distance, and maximum parsimony methods. Mol Biol Evol 2011. 28: p. 2371-2739.

21. Muhire, B., et al., A genome-wide pairwise-identity-based proposal for the classification of viruses in the genus Mastrevirus (family Geminiviridae). Arch Virol, 2013. 158(6): p. 1411-1424.

22. Tamura, K. and M. Nei, Estimation of the number of nucleotide substitutions in the control region of mitochondrial DNA in humans and chimpanzees. Mol Biol Evol, 1993. 10(3): p. 512-526.

23. Higgins, C.M., et al., Diversity and evolutionary history of Lettuce necrotic yellows virus in Australia and New Zealand. Arch Virol, 2016. 161(2): p. 269-277.

24. Ali, A., et al., Analysis of genetic bottlenecks during horizontal transmission of Cucumber mosaic virus. J Virol, 2006. 80(17): p. 8345-8350.

25. Canto, T., M.A. Aranda, and A. Fereres, Climate change effects on physiology and population processes of hosts and vectors that influence the spread of hemipteran-borne plant viruses. Global Change Biol, 2009. 15(8): p. 1884-1894. 